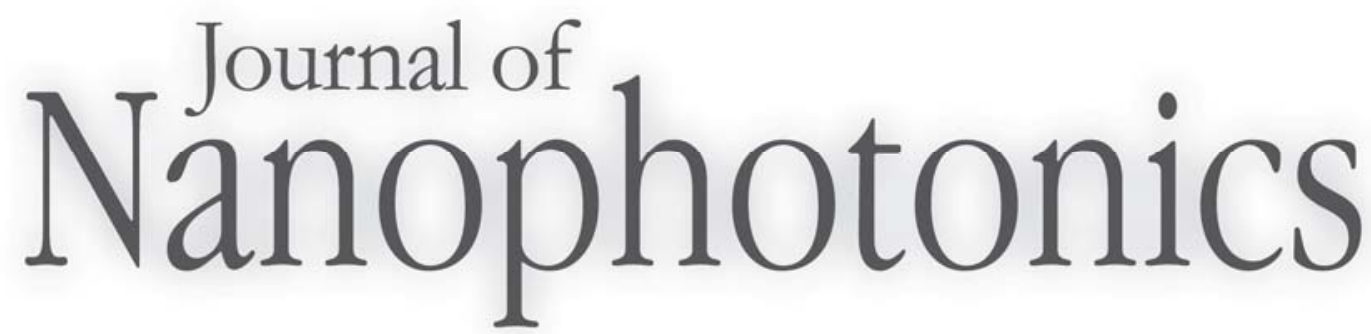

SPIEDigitalLibrary.org/jnp

\title{
Editorial: Sustainability research and sustainable research
}

Akhlesh Lakhtakia 


\title{
Editorial: \\ Sustainability research and sustainable research
}

\author{
Akhlesh Lakhtakia \\ Editor-in-Chief
}

As I write this editorial on Earth Day 2010, I am mindful of volcanic ash clouding European skies; the recent earthquakes in China, Haiti, and Chile; and the tsunami that wreaked havoc some years ago from Indonesia to Somalia. I am also thinking of a recent investigative report from the Pennsylvania State University and another from the University of East Anglia on the alleged Climategate.

Instant journalism certainly sweeps up shocking news everyday to our thresholds. Not being a climatologist, I do not know if the incidence of natural catastrophes has recently increased, or merely its worldwide reportage. Regardless, these catastrophes warn us of the fragility of our ecosystems and remind us that the continued presence of life in just one of the many satellites of our sun is quite a miracle. Looking around the urban sprawl in State College, PA, USA, where I have lived more than a quarter of century, as well as in Lucknow and Delhi, India, where I was born and raised, I can see that our ways of living are not sustainable. I do not need a hockey-stick graph, even if slightly "improved," of global warming to convince me of that observation.

"Drill, baby, drill" may be perceived as an economic necessity by some sections of the public, and may indeed be an economic necessity today, but it can bring only temporary respite. Hence, the sharp focus of many national and international organizations today on sustainable sources of energy and food, waste reduction and pollution prevention, and environmental consciousness is laudable. It is in this context that SPIE has launched the new Journal of Photonics for Energy, with Zakya Kafafi as its Editor-in-Chief. A warm welcome to the new journal!

While research on sustainability is much to be commended, research on other technoscientific topics must become sustainable. Technoscientific research is essential, and we still have billions of minds to harness for it, but already the increased number of research papers and conference presentations over the last two decades is marked by a huge degree of duplication. Some duplication is necessary so that we can be sure of new results, but only some. Massive duplication of research efforts is eating up significant societal resources across the globe. Races for research funding are wasting the time needed for thoughtful action on writing and rewriting research proposals, many of which are similar in content. Personal incentives offered by governments to boost research are stifling innovation by promoting duplicative incrementalism at best and plagiarism at worst. Similar, and often the same, presentations are made at diverse conferences by the same researchers-which practice is doubly grating when one considers the amount of carbon dioxide emitted during gasolinepowered travel, not to mention the increased consumption of high-calorie foods and disturbances in sleep patterns while attending conferences away from home. Research empires form and a resource-grabbing mindset flourishes. Research progress is measured in terms of continued expenditures on new equipment, floor area, and personnel. Research productivity is simplified to a few numbers.

Let us researchers not emulate lemmings. This is neither a call to collective passivism nor an appeal to fetter individual dynamism, but suggests the adoption of a different perspective instead.

Already the fruits of earlier technoscientific research are beginning to help form that perspective. Almost all major journals are also published online, and many new journals are published only online. Lectures on advanced topics are being placed on the web. Webinars 
can replace many small conferences. The organizers of large conferences ought to cooperate not only to avoid repetition of session themes but also to convene in different but accessible locations worldwide. University administrators ought not to take delight in increased research expenditures but on enhanced relevance to society and the globe. National and institutional research budgets ought to project not only the monies to be spent but also the degree of deforestation to be arrested or, even better, reversed.

The conduct of research must become frugal and sustainable. 